\title{
IMPACT OF TURBULENCE MODELS OF WIND PRESSURE ON TWO BUILDINGS WITH ATYPICAL CROSS-SECTIONS
}

\author{
Michal FRANEK ${ }^{1, *}$, Marek MACÁK², Olga HUBOVÁ ${ }^{3}$, Ol'ga IVÁNKOVÁ \\ ${ }^{1}$ Department of Building Construction, Faculty of Civil Engineering STU in Bratislava, 81005 \\ Bratislava, Slovakia. \\ ${ }^{2}$ Department of Mathematics and Descriptive Geometry, Faculty of Civil Engineering STU in \\ Bratislava, 81005 Bratislava, Slovakia. \\ ${ }^{3}$ Department of Structural Mechanics, Faculty of Civil Engineering STU in Bratislava, 81005 \\ Bratislava, Slovakia. \\ corresponding author: michal.franek@stuba.sk
}

\begin{abstract}
The article deals with the numerical analysis of the wind pressure distribution on a group of two high-rise buildings of different shape for different wind directions. The first building has the shape of a circular cylinder and the second was created by a combination of semicircles and a longitudinal member. The floor plan of the second building was similar to the letter $S$. The simulations were realized as $3 D$ steady RANS. CFD results were compared with experimental measurements in the wind tunnel of the Slovak University of Technology in Bratislava. The results were processed using statistical methods such as correlation coefficient, fractional bias and fraction of data within a factor of 1.3, which determined the most suitable CFD model. The purpose of the present article was to verify the distribution of the external pressure coefficient on scale models at a scale of 1:350, which are located in the Atmospheric Surface Layer (ASL). In numerical modeling, the most important thing was to ensure similarity with the flow in the experimental Atmospheric Boundary Layer (ABL) and with the flow around the models. SST $k-\omega$ was evaluated as the most suitable turbulent model for the given type of problem. Turbulent models had a decisive influence on the overall distribution of external wind pressures on objects. The results showed that the most suitable orientation of the objects in terms of the external wind pressure coefficient is $0^{\circ}$, when the cylinder produced a shielding effect, with min mean $c_{p e}=-0.786$. The most unfavorable wind effects were shown by the wind direction of $90^{\circ}$ and $135^{\circ}$ with the value min mean $c_{p e}=-1.361$
\end{abstract}

\section{Keywords:}

Atypical cross-section; External pressure coefficient; Wind tunnel; Computational fluid dynamics.

\section{Introduction}

The advances and increasing accuracy of computer simulations lead to a significant increase in applications in wind engineering. Regarding problematic areas, especially in modelling the boundary layer of the atmosphere, it is necessary to develop simulation programs in cooperation with experimental measurements in wind tunnels. The use and combination of these solutions can lead to a more accurate understanding of the phenomenon of turbulent flow. The methods of numerical and experimental simulation can be specified on the basis of their comparison and their strengths and weaknesses can be sought [1 - 4]. The area dealing with simulation methods in wind engineering is called Computational Wind Engineering (CWE). CWE is primarily defined as the use of computational fluid dynamics (CFD) for wind engineering, although it includes other approaches to computer modelling as well as field and wind tunnel measurements supporting the development and evaluation of CWE models [3]. Compared to experimental measurements, the use of computational simulation of wind flow is a relatively cheap and fast solution. We see the main advantage in that it provides a 
complete picture of the flow in the whole computational area and it is possible to model objects in full, which eliminates problems with similarity parameters. On the other hand, we see less accuracy and reliability as the main disadvantage. The error and accuracy of the results is caused by the large number of parameters that enter the simulation and are entered by the user. Therefore, it is necessary to implement these methods in combination with experimental measurements.

There are several principles for solving the model itself in a computer simulation environment. It can be a scientific model of reality, a mathematical model based on a scientific model and a discrete numerical model of a continuous numerical model, an application-program model of a numerical model and a computational model of an application model [5]. In order to be able to use a specific model for building practice, it is necessary to subject it to verification and validation. Verification consists of the process of checking a mathematical model for correct representation and mathematical accuracy. This process involves checking theoretical inputs and assumptions to verify that the model does not contain unacceptable mathematical errors compared to the experiment. Validation determines the degree of accuracy of the achieved results for application in real conditions.

The history of the development of simulation programs and computational methods in CWE dates back to the 50s of the last century [6,7]. A detail process of CFD development in CWE can be found in the works of Blocken [3], Murakami and Mochid [8]. Gradually improved simulation models also revealed new problems and limits that had to be faced. Specific problems that arose were flow around bluff bodies, sharp-edged bodies, boundary layer modelling, influence of the Reynolds number, complex properties of 3D flow, separation and vortex shedding [9]. These limitations have resulted from physical modelling limitations and computer performance limits. However, we still meet many of them to some extent today. The work of Richards and Hoxey [10] pointed to the problem of Atmospheric Surface Layer (ASL) modelling. The approach flow was modelled as homogenous flow, where the mean velocity and turbulence profiles were compared with the $k-\varepsilon$ turbulent profile. The numerical solution was compared with full-scale measurements at Silsoe cube using sonic anemometers. Other works dealing with the equilibrium atmospheric boundary layer in the computational domain are in [11-13]. Bluff body aerodynamics have been studied by Murakami et al. [14-16], where turbulent flow, pressure distributions and wind forces were investigated using various turbulent models.

The article deals with the analysis of various turbulent RANS models in the ANSYS Fluent program environment. Namely, these are turbulent models:

- Standard $k-\varepsilon[17]$

- Realizable $k-\varepsilon[18]$,

- Standard $k-\omega[19]$,

- Shear Stress Transport $k-\omega[20]$.

The numerical results were compared with the results of experimental measurements performed in the wind tunnel of the Slovak University of Technology in Bratislava (BLWT). Subsequently, the most optimal numerical model was evaluated using statistical methods, which was further used. With the selected turbulent model, a detailed analysis of the distribution of wind pressures for different wind directions for atypical models of objects was performed. From the numerical analysis of the results, zones loaded by increased levels of pressure and suction for cladding were evaluated.

\section{Wind tunnel tests}

\subsection{Description of the boundary layer wind tunnel (BLWT) and instrumentation equipments}

Simulation of the Atmospheric Boundary Layer (ABL) and pressure measurement tests were carried out in the Boundary Layer Wind Tunnel in Bratislava [21]. It is a low-speed wind tunnel whose cross-working section measures $2.6 \times 1.6 \mathrm{~m}$. Length of wind tunnel is $26.2 \mathrm{~m}$. The approaching flow corresponded to the wind flow through urban terrain with aerodynamic roughness length $z_{0}=0.7 \mathrm{~m}$ in full scale. Mean wind velocity and turbulence intensity profiles were compared with Eurocode [22] categorization and were classified between terrain category III and IV. The experiment was performed for two reference wind speeds of 11.359 and $13.616 \mathrm{~m} / \mathrm{s}$, which were measured at the roof level of the model. All experimental measurements were performed in accordance with the recommendations of the American Society of Civil Engineers (ASCE) [23].

Wind pressures were synchronously measured by Pneumatic transducer DSA 3217 made by Scanivalve with a rate of 500 samples/chan/sec. Reference velocity was measured with Hot-Wire 
Anemometer MiniCTA 54T42 with miniature wire straight probe, type 55P11 from Dantec Dynamics. A static Pitot tube was used to measure static pressure.

\subsection{Geometry, arrangements of models and location of the pressure taps}

Experimental measurements were performed on scale models at a scale of 1:350. The first model was a circular cylinder with a diameter of $110 \mathrm{~mm}$ and a height of $300 \mathrm{~mm}$. Second, an atypical model was designed by combining two semicircles and a rectangle with a floor plan in the shape of the letter S. Detailed experimental and numerical study of the stand-alone $S$ shape building was published by Medvecká et al. [24]. The total width and length were $150 \mathrm{~mm}$, height $300 \mathrm{~mm}$. The models were placed in close proximity at a distance of $75 \mathrm{~mm}$ from the outer walls of the models in order to maximize interaction. The detailed geometry and arrangement of the models is shown in Fig. 1. Multiple wind directions from $0-360^{\circ}$ with rotation of $22.5^{\circ}$ were verified experimentally. Pressure samples were placed on each model in three levels, bottom, center and top. The circular cylinder had 12 samples in each level. The atypical cylinder had 24 samples at each height level, see Fig. 1. The recording time for each measurement was $20 \mathrm{~s}$ with a sampling frequency of $500 \mathrm{~Hz}$. Differential pressures were recorded from each pressure sample, from which the mean value of the external wind pressure coefficient was then calculated according to the relation:

mean $c_{p e}=\frac{p-p_{s}}{\frac{1}{2} \rho u_{r e f}^{2}}$,

where mean $c_{p e}$ is external mean pressure coefficient $(-), p$ is mean local surface pressure in tap [Pa], $p_{s}$ is free stream mean static pressure $[\mathrm{Pa}], \rho$ is the physical density of air in $\mathrm{kg} / \mathrm{m}^{3}$, and $u_{\text {ref }}$ is the free stream mean reference velocity, in our case at the top of a model [m/s], which was set as 11.359 and $13.616 \mathrm{~m} / \mathrm{s}$.

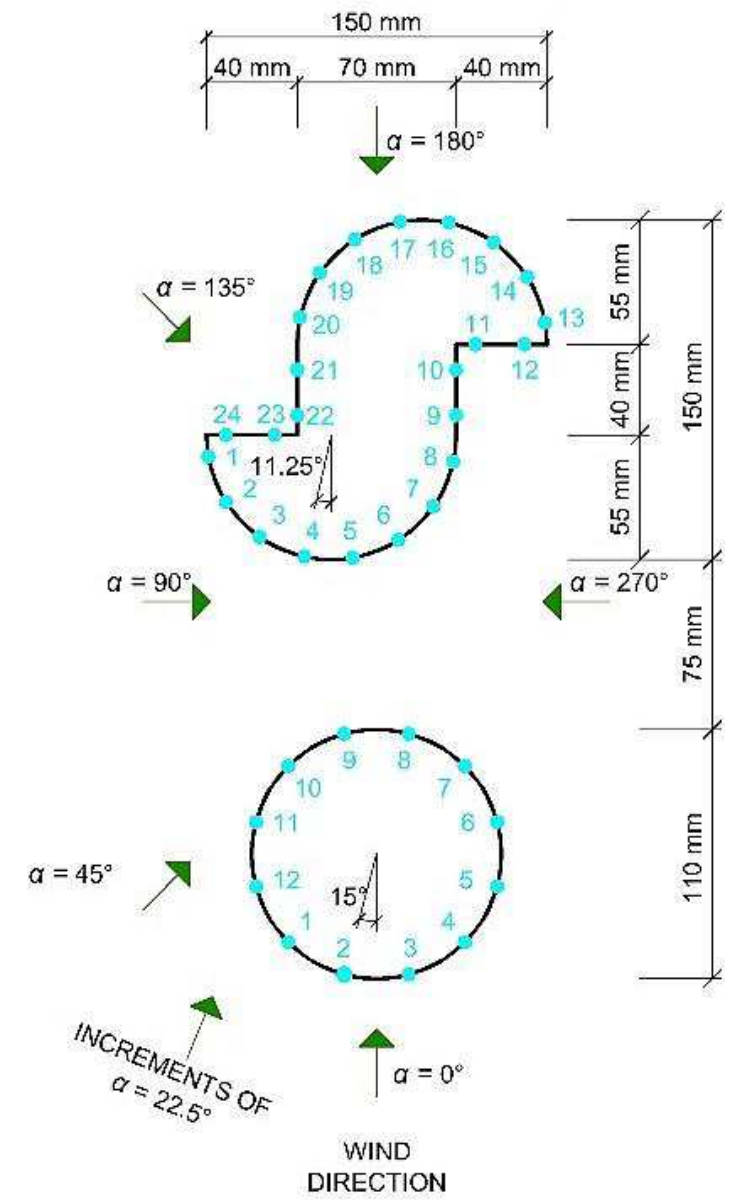

Fig. 1: Geometry and arrangements of the models. 


\section{CFD simulations}

Numerical simulation was performed in the program ANSYS Fluent, which allows a detailed definition of the problem and its solution and contains the most comprehensive set of mathematical models used in many applications. Computer fluid simulation for the buildings was prepared. For the solution of the 3D steady RANS equations with Standard $k-\varepsilon$ [17], Realizable $k-\varepsilon$ [18], Standard $k-\omega$ [19], Shear Stress Transport $k-\omega$ [20] we used CFD code ANSYS Fluent, which solves Navier Stokes equations along with the added two equations.

\subsection{Computational domain and grid}

The size of the calculation area was designed to match the wind tunnel measurement conditions, see Fig. 2. Domain bottom from rough wall function was consistent to the wind tunnel floor with a long fetch of roughness elements from the dimpled membrane with a height of $20 \mathrm{~mm}$. The size of the domain was $W \times H \times L=2.6 \times 1.6 \times 6 \mathrm{~m}^{3}$, where the width and height were identical to the wind tunnel cross-section. The recommendation maximum blockage ratio $3 \%[12,25]$ was fulfilled. The computational grids were generated according to the generation techniques introduced in $[4,26]$ and some Fluent Meshing program limitations. The grid was created from elements with maximization of numerical accuracy; the grid resolution on the model surfaces was $0.001 \mathrm{~m}$. The size of the first nearwall cell was $0.001 \mathrm{~m}$ in order to keep the value of the dimensionless wall unit $y^{+}$in the logarithmic law interface between 30 and 300 . In total, the computational network contained approximately 1 million cells.

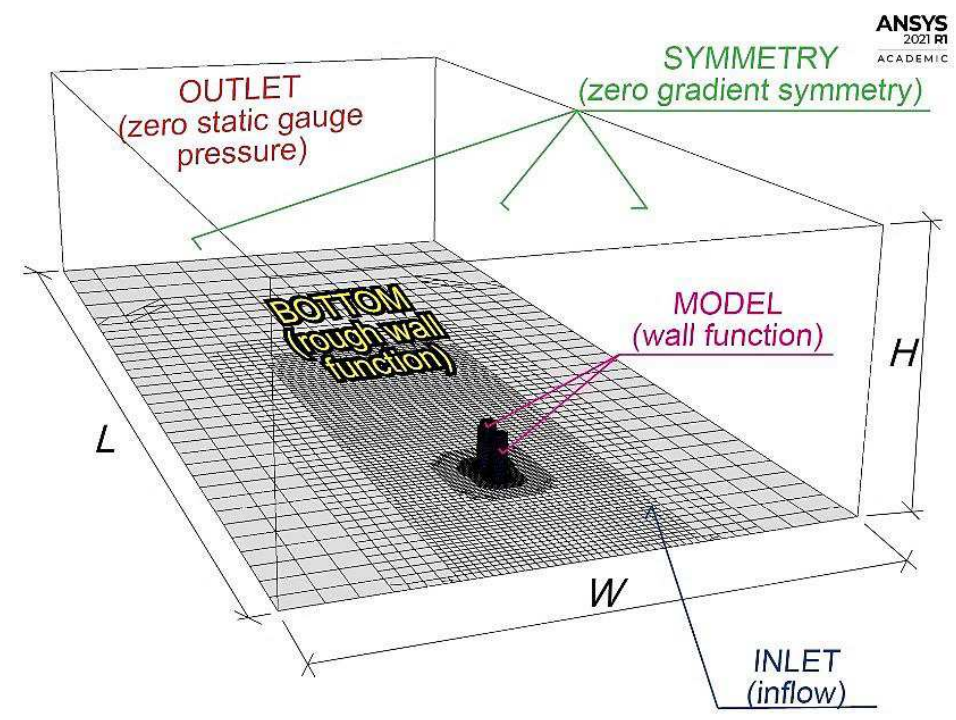

Fig. 2: Computational domain and surface grid for wind direction $\alpha=0^{\circ}$ with the boundary conditions.

\section{2 Boundary conditions}

According to experimental setup of $A B L$, it was proper to use at inlet logarithmic wind profile with aerodynamic roughness length $z_{0}=0.00179 \mathrm{~m}$ in tunnel scale. The reference velocity at a top of a model $z_{\text {ref }}=0.300 \mathrm{~m}$ was $13.616 \mathrm{~m} / \mathrm{s}$. Additional inputs for $k-\varepsilon$ and $k-\omega$ turbulence models were calculated as follows

$k=\frac{u^{* 2}}{\sqrt{C_{\mu}}}$,

$\varepsilon(z)=\frac{u^{* 3}}{\kappa\left(z+z_{0}\right)}$,

$\omega(z)=\frac{\varepsilon(z)}{k}$, 
where $u^{*}$ is shear velocity [28], $C_{\mu}=0.09$ is a model constant, $\kappa$ is von Kármán constant equal to 0.42 , $z$ is the height, $z_{0}$ is the aerodynamic roughness length. The bottom boundary was simulated as a rough wall. The sand-grain roughness height $k_{s}$ was calculated by

$k_{s}=\frac{9.793 z_{0}}{C_{s}}$.

The roughness constant $C_{s}$ was set equal to 5 [11]. The pressure outflow was defined at outlet boundary, the side, and the upper boundary as zero gradient symmetry, see Fig. 2.

\subsection{The turbulence models}

For CFD simulation, we chose ANSYS [27] using the 3D steady Reynolds Averaged NavierStokes equations (RANS) turbulence models, namely: Standard $k-\varepsilon$ [17], Realizable $k-\varepsilon$ [18], Standard $k-\omega[19]$, Shear Stress Transport $k-\omega[20]$.

The governing equations of the Standard $k-\varepsilon$ model were:

$\rho \frac{\partial k}{\partial t}+\rho \operatorname{div}(k \vec{V})=\operatorname{div}\left(\mu+\frac{\mu_{t}}{\sigma_{k}} \operatorname{grad} k\right)+P_{k}-\rho \varepsilon-Y_{M}+S_{k}$,

$\rho \frac{\partial \varepsilon}{\partial t}+\rho \operatorname{div}(\varepsilon \vec{V})=\operatorname{div}\left(\mu+\frac{\mu_{t}}{\sigma_{\varepsilon}} \operatorname{grad} \varepsilon\right)+C_{1 \varepsilon} \frac{\varepsilon}{k} P_{k}-C_{2 \varepsilon} \rho \frac{\varepsilon^{2}}{k}+S_{\varepsilon}$.

The governing equations of the Realizable $k-\varepsilon$ model were:

$\rho \frac{\partial k}{\partial t}+\rho \operatorname{div}(k \vec{V})=\operatorname{div}\left(\mu+\frac{\mu_{t}}{\sigma_{k}} \operatorname{grad} k\right)+P_{k}-\rho \varepsilon-Y_{M}+S_{k}$,

$\rho \frac{\partial \varepsilon}{\partial t}+\rho \operatorname{div}(\varepsilon \vec{V})=\operatorname{div}\left(\mu+\frac{\mu_{t}}{\sigma_{\varepsilon}} \operatorname{grad} \varepsilon\right)+\rho C_{1} S_{\varepsilon}-\rho C_{2 \varepsilon} \frac{\varepsilon^{2}}{k+\sqrt{v \varepsilon}}+S_{\varepsilon}$,

where $\rho$ is the physical density of air, $t$ is time, $\vec{V}$ is mean wind velocity vector, $k$ is turbulent kinetic energy, $\varepsilon$ is turbulent dissipation rate, $\mu$ is dynamic molecular viscosity, $\mu_{t}$ is dynamic turbulent viscosity, $\sigma_{k}$ and $\sigma_{\varepsilon}$ are Prandtl numbers for $k$ and $\varepsilon, P_{k}$ is the generation of the turbulent kinetic energy due to the mean speed gradient, $Y_{M}$ is dilatation dissipation term, $C_{1}, C_{1 \varepsilon}, C_{2 \varepsilon}$ are model constants, $v$ is kinematic molecular viscosity, $S_{k}$ and $S_{\varepsilon}$ are the source term for $k$ and $\varepsilon$.

The governing equations of the Standard $k-\omega$ model were:

$\rho \frac{\partial k}{\partial t}+\rho \operatorname{div}(k \vec{V})=\operatorname{div}\left(\mu+\frac{\mu_{t}}{\sigma_{k}} \operatorname{grad} k\right)+P_{k}-Y_{k}+S_{k}$,

$\rho \frac{\partial \omega}{\partial t}+\rho \operatorname{div}(\omega \vec{V})=\operatorname{div}\left(\mu+\frac{\mu_{t}}{\sigma_{\omega}} \operatorname{grad} \omega\right)+P_{\omega}-Y_{\omega}+S_{\omega}$,

The governing equations of the SST $k-\omega$ model were:

$\rho \frac{\partial k}{\partial t}+\rho \operatorname{div}(k \vec{V})=\operatorname{div}\left(\mu+\frac{\mu_{t}}{\sigma_{k}} \operatorname{grad} k\right)+P_{k}-Y_{k}+S_{k}$,

$\rho \frac{\partial \omega}{\partial t}+\rho \operatorname{div}(\omega \vec{V})=\operatorname{div}\left(\mu+\frac{\mu_{t}}{\sigma_{\omega}} \operatorname{grad} \omega\right)+P_{\omega}-Y_{\omega}+D_{\omega}+S_{\omega}$,

where $P_{\omega}$ is the rate of production of $k$ and generation of the $\omega, Y_{k}$ and $Y_{\omega}$ represent the dissipation terms of $k$ and $\omega$ due to the turbulence, $D_{\omega}$ is cross-diffusion term and $S_{\omega}$ is the source term for $\omega$.

Listed equations are given as general equations. Numerical simulations represented steady isothermal incompressible flow. Terms as buoyancy, compressible turbulence and source terms did not correspond with the given problem.

\subsection{Other settings}

All simulations ran as pressure-based, steady, without production limiter and curvature correction. The SIMPLE algorithm with the second-order spatial discretisation was used. The simulations were done when scaled residuals reached the minimal values: $10^{-5}$ in all quantities. The 
simulations were performed using parallel processing on a desktop computer with one Intel Core i78700K 3.7 GHz processor and $64 \mathrm{~GB}$ DDR4 memory.

\section{Results and discussion}

Experimental measurements and numerical results were compared and evaluated using statistical methods. The results were evaluated and commented in terms of the mean value of the external pressure coefficient mean $c_{p e}$ for sampling points on the models, for 5 wind directions 0,45 , 90,135 and $180^{\circ}$. In the last part, the most suitable CFD setting and the selection of a turbulent model are evaluated. Subsequently, on the basis of the selected turbulent model, the extremes of pressures and suctions are verified, which appear on the models in different wind directions from the point of view of the perimeter cladding.

\subsection{Deviation and statistical metrics with an experiment}

For validations of the CFD results were used statistical metrics: fractional bias $F B$, correlation coefficient $R$ and the fraction of data within a factor of 1.3, FAC1.3, [28]. These metrics were calculated using the following equations:

$$
\begin{aligned}
& F B=2 \frac{\bar{X}-\bar{Y}}{\bar{X}+\bar{Y}}, \\
& R=\frac{\operatorname{cov}(X, Y)}{\sigma_{X} \sigma_{Y}},
\end{aligned}
$$

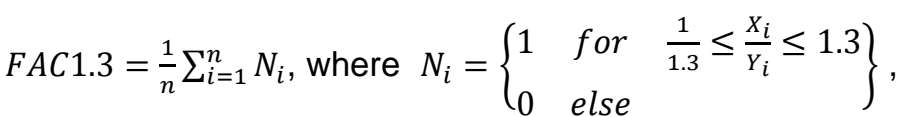

where $\bar{X}$ is average of the samples of mean $c_{p e}$ from the wind tunnel, $X$ is mean $c_{p e}$ value from the wind tunnel, $\bar{Y}$ is average of the samples of mean $c_{p e}$ from the CFD results, $Y$ is mean $c_{p e}$ value from the CFD results, cov is the covariance and $\sigma_{X}$, and $\sigma_{Y}$ is the standard deviation for $X$ and $Y$.

The ideal values matching better accuracy between WT and CFD results are $F B=0, R=1$ and $F A C 1.3=1$. Results from $S$ shape and cylindrical building compared with statistical metrics are shown in Table 1 and 2. In Table 1 it can be seen that for the wind direction $0^{\circ}$, the CFD results gave higher values, which is a negative FB value. With wind directions higher than $45^{\circ}$, a change occurs where SKE and RKE show an underestimation of the results compared to the experiment. This is not so clear for the SKO and SST models. For wind directions 0 and $45^{\circ}$, these models show higher values, for directions 90 to $180^{\circ}$ there is a slight underestimation of the results. Overall, the SKO and SST turbulence models are more accurate in terms of FB value. If we look at the correlation of CFD versus WT, the results from the experiment correlate better with the SKO and SST models. When comparing all solved wind directions, the SST model is the most accurate one. We explain the more accurate results compared to the SKE and RKE models by the fact that the $k-\omega$ models better estimate the negative pressure gradient, the modelled boundary layer and the flow separation at the edges of the $S$ shape building. In Fig. 3 there can be seen the correlation between WT and CFD models for wind direction $0^{\circ}$. From these results, the zones loaded by pressure show a greater variance than WT. The error rate in most cases exceeded $30 \%$. Zones loaded by suction are having a lower percentage of error, in most cases below $30 \%$. Distortion of the results can be caused by the cylinder that creates the shield and shedding vortices in front of the $S$ shape building.

In Table 2, the results for cylindrical building are processed. From the comparison of FB values it is clear that the results from all turbulence models showed a slight decrease in values compared to the experiment. The SST model gave the most accurate results when comparing the correlation and FAC1.3. Fig. 4 shows a similar trend, where the zones loaded by the pressures show a higher percentage of error rate than the zones loaded by the suction. 
Table 1: Statistical evaluation of CFD results with WT results of the S shape building at 84 measurement positions, for wind directions $\alpha=0,45,90,135$ and $180^{\circ}$.

\begin{tabular}{|c|c|c|c|c|c|}
\hline $\boldsymbol{\alpha}=\mathbf{0}^{\circ}$ & SKE vs BLWT & RKE vs BLWT & SKO vs BLWT & SST vs BLWT & Ideal values \\
\hline FB & -0.504 & -0.402 & -0.488 & -0.306 & 0.0 \\
\hline$R$ & 0.937 & 0.934 & 0.936 & 0.964 & 1.0 \\
\hline FAC1.3 & 0.595 & 0.536 & 0.619 & 0.762 & 1.0 \\
\hline$\alpha=\mathbf{4 5}^{\circ}$ & SKE vs BLWT & RKE vs BLWT & SKO vs BLWT & SST vs BLWT & Ideal values \\
\hline FB & 0.213 & 0.142 & -0.039 & -0.041 & 0.0 \\
\hline$R$ & 0.958 & 0.948 & 0.962 & 0.950 & 1.0 \\
\hline FAC1.3 & 0.821 & 0.857 & 0.857 & 0.881 & 1.0 \\
\hline$\alpha=90^{\circ}$ & SKE vs BLWT & RKE vs BLWT & SKO vs BLWT & SST vs BLWT & Ideal values \\
\hline FB & 0.486 & 0.943 & 0.295 & 0.123 & 0.0 \\
\hline$R$ & 0.967 & 0.982 & 0.986 & 0.990 & 1.0 \\
\hline FAC1.3 & 0.774 & 0.702 & 0.762 & 0.964 & 1.0 \\
\hline$\alpha=135^{\circ}$ & SKE vs BLWT & RKE vs BLWT & SKO vs BLWT & SST vs BLWT & Ideal values \\
\hline FB & 0.918 & 0.730 & 0.353 & 0.246 & 0.0 \\
\hline$R$ & 0.971 & 0.982 & 0.992 & 0.986 & 1.0 \\
\hline FAC1.3 & 0.810 & 0.917 & 0.940 & 0.952 & 1.0 \\
\hline$\alpha=180^{\circ}$ & SKE vs BLWT & RKE vs BLWT & SKO vs BLWT & SST vs BLWT & Ideal values \\
\hline FB & 0.114 & 0.099 & 0.014 & -0.050 & 0.0 \\
\hline R & 0.936 & 0.894 & 0.903 & 0.900 & 1.0 \\
\hline FAC1.3 & 0.917 & 0.917 & 0.889 & 0.917 & 1.0 \\
\hline
\end{tabular}

Table 2: Statistical evaluation of CFD and WT results of the cylindrical building at 36 measurement positions, for wind directions $\alpha=0,45,90,135$ and $180^{\circ}$.

\begin{tabular}{|c|c|c|c|c|c|}
\hline $\boldsymbol{\alpha}=\mathbf{0}^{\circ}$ & SKE vs BLWT & RKE vs BLWT & SKO vs BLWT & SST vs BLWT & Ideal values \\
\hline FB & 0.986 & 0.835 & 0.503 & 0.334 & 0.0 \\
\hline $\mathrm{R}$ & 0.967 & 0.978 & 0.992 & 0.992 & 1.0 \\
\hline $\mathrm{FAC1.3}$ & 0.833 & 0.869 & 0.929 & 0.964 & 1.0 \\
\hline $\boldsymbol{\alpha}=\mathbf{4 5}{ }^{\circ}$ & SKE vs BLWT & RKE vs BLWT & SKO vs BLWT & SST vs BLWT & Ideal values \\
\hline FB & 0.195 & 0.253 & -0.004 & 0.058 & 0.0 \\
\hline $\mathrm{R}$ & 0.933 & 0.950 & 0.952 & 0.955 & 1.0 \\
\hline FAC1.3 & 0.639 & 0.750 & 0.694 & 0.778 & 1.0 \\
\hline$\alpha=90^{\circ}$ & SKE vs BLWT & RKE vs BLWT & SKO vs BLWT & SST vs BLWT & Ideal values \\
\hline FB & 0.163 & 0.219 & 0.037 & 0.185 & 0.0 \\
\hline$R$ & 0.955 & 0.966 & 0.966 & 0.969 & 1.0 \\
\hline FAC1.3 & 0.750 & 0.806 & 0.861 & 0.861 & 1.0 \\
\hline$\alpha=135^{\circ}$ & SKE vs BLWT & RKE vs BLWT & SKO vs BLWT & SST vs BLWT & Ideal values \\
\hline FB & 0.088 & 0.289 & 0.112 & 0.163 & 0.0 \\
\hline$R$ & 0.900 & 0.908 & 0.914 & 0.901 & 1.0 \\
\hline FAC1.3 & 0.667 & 0.667 & 0.806 & 0.778 & 1.0 \\
\hline$\alpha=180^{\circ}$ & SKE vs BLWT & RKE vs BLWT & SKO vs BLWT & SST vs BLWT & Ideal values \\
\hline FB & 0.879 & 0.550 & 0.335 & 0.199 & 0.0 \\
\hline R & 0.930 & 0.943 & 0.947 & 0.959 & 1.0 \\
\hline FAC1.3 & 0.583 & 0.611 & 0.694 & 0.778 & 1.0 \\
\hline
\end{tabular}




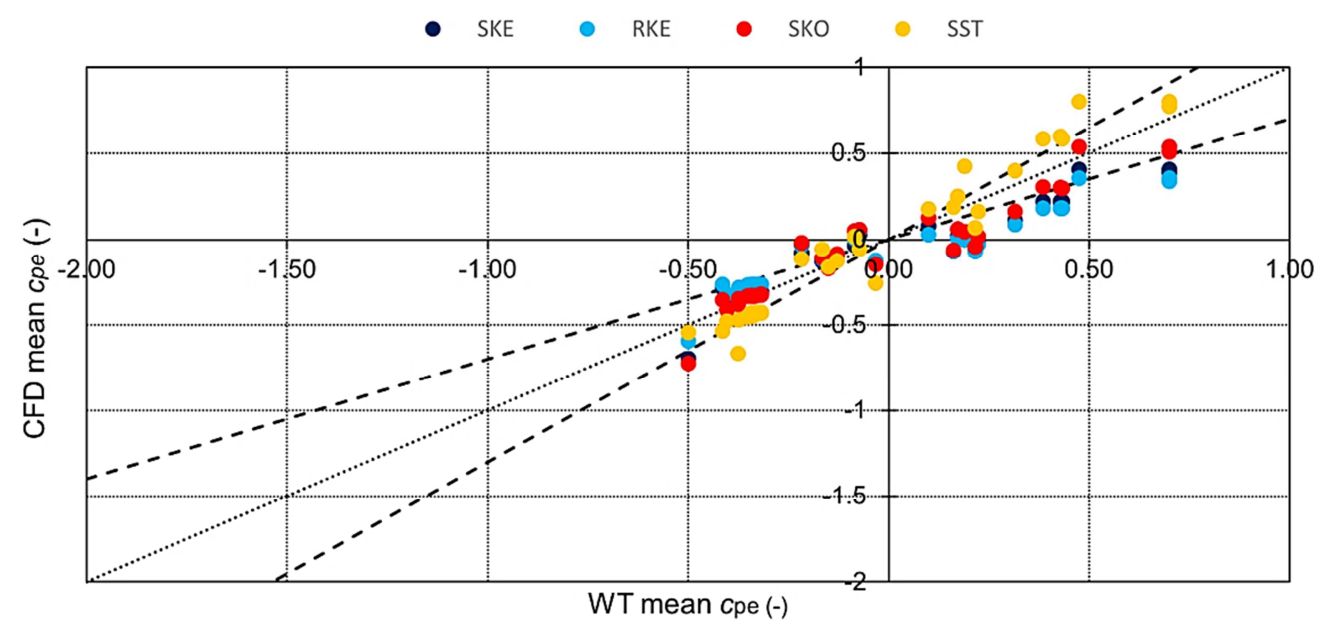

Fig. 3: Correlation of CFD with wind tunnel (WT) results from $S$ shape in terms of mean $c_{p e}$ for wind directions $\alpha=0^{\circ}$. Dashed black lines correspond to $30 \%$ errors.

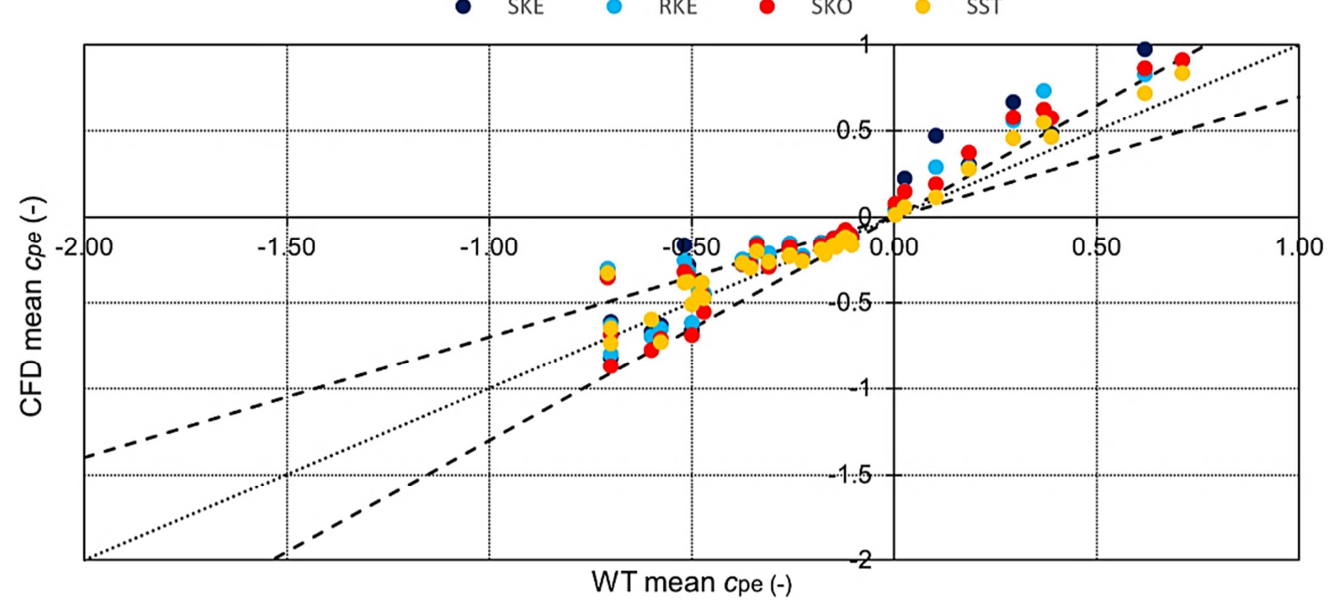

Fig. 4: Correlation of CFD with wind tunnel (WT) results from cylinder in terms of mean $c_{p e}$ for wind directions $\alpha=0^{\circ}$. Dashed black lines correspond to $30 \%$ errors.

\subsection{Extremes of $c_{p e}$ on the whole cladding from CFD results}

Based on the calibration of WT results with CFD results, the most optimal setting and turbulent model SST $k-\omega$ was selected. Pressure samples equivalent to experimental samples were used for calibration. From these results, it is not possible to say with certainty whether the experiment captured critical points in terms of pressure distribution. Therefore, a calibrated CFD was used to give an overall picture of wind load. From the results for wind directions from $0-180^{\circ}$ with increments of $45^{\circ}$, extreme values of pressures and suctions on the perimeter cladding and roof were analyzed. From the analysis of different wind directions it was found that the most critical wind directions were $\alpha=90^{\circ}$ and $135^{\circ}$. The influence of the wind direction and near standing building was most pronounced on the $S$ shape building. In Fig. 5 it can be seen that the range of positive pressures did not have a significant effect on the load. The building standing around creates the so-called shielding effect, which partially reduces pressures. Suction has the greatest impact of the wind load on the facade. From Fig. 5 it can be seen that the most problematic behavior is the negative pressure zone in the wind direction $\alpha=$ $90^{\circ}$. The channelling effect was confirmed here, i.e. narrowing between buildings, see Fig. 5a where mean $c_{p e}=-1.361$. In the wind direction $\alpha=135^{\circ}$, however, due to asymmetrical flow and gentle rotation of the models, an extreme arose in the outer inlet zone, see. Fig. 5b, which represented external mean wind coefficient $c_{p e}=-1.256$.

A significant reduction in the increased suction values occurred when arranging the objects in a row, i.e. $\alpha=0$ and $180^{\circ}$. The buildings created a shielding effect between them. The most significant reduction was for the wind direction $\alpha=0^{\circ}$, where the maximum value of suction was reduced to the value mean $c_{p e}=-0.786$, see Fig. $5 \mathrm{c}$. 


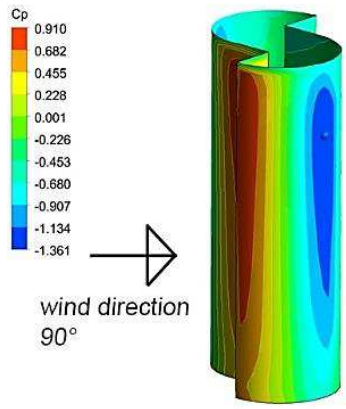

a)

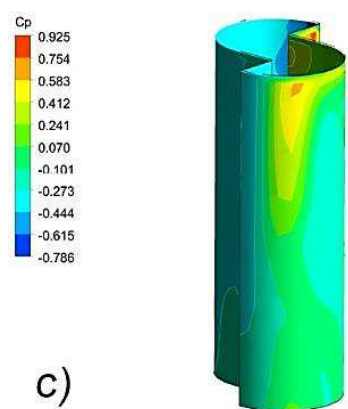

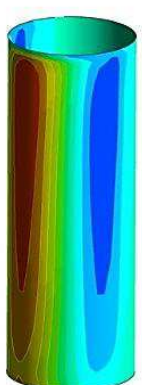

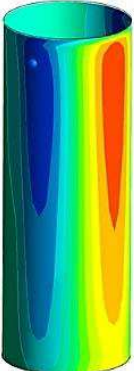

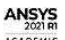

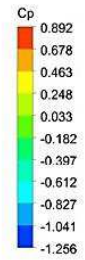

b)

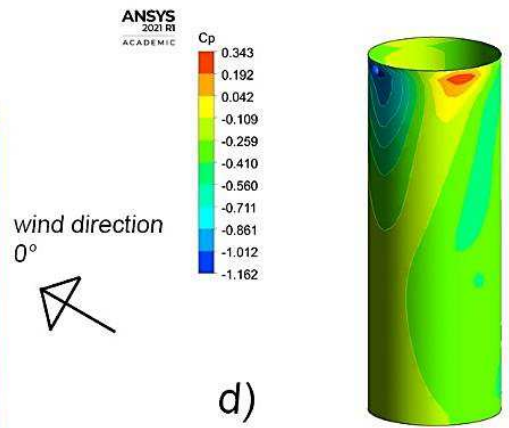

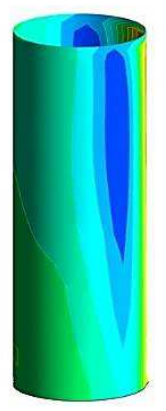

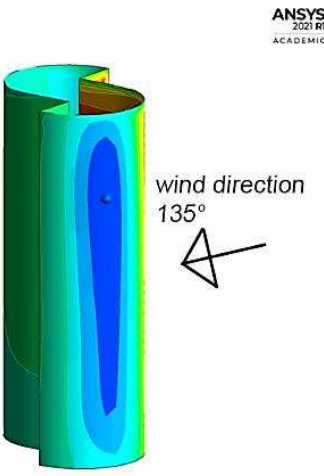

ANSYS
ACO21
ACAOEMIC

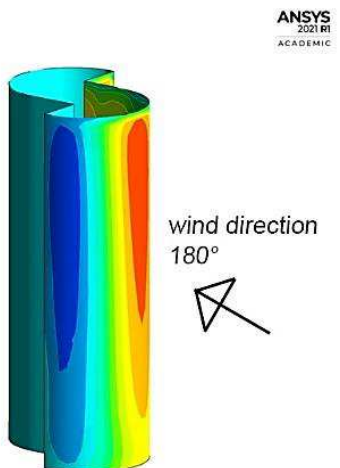

Fig. 5: Distribution of mean $c_{p e}$ for: critical wind directions a) $\alpha=90^{\circ}$ and b) $\alpha=135^{\circ}$, optimal wind directions c) $\alpha=0^{\circ}$ and d) $\alpha=180^{\circ}$; the blue sphere shows the maximal suction zone on buildings.

\section{Conclusions}

3D steady RANS approach with various turbulent models was used to verify the pressure distribution on the cladding of atypical buildings. The settings of the simulation program were used with respect to the range of solved areas and wind directions. We know that 3D steady RANS models have certain limitations and shortcomings, such as predicting flow separation, wake and reversal zones. However, the use of more complex types of simulations such as Large Eddy Simulation (LES) and Direct Numerical Simulation (DNS) would require a finer computational grid and an unsteady simulation solution with small time steps. This would increase both time and computational complexity. In terms of the presented results and conclusions, we evaluate the use of 3D steady RANS models as suitable for preliminary analysis of the results and their use for further research.

The effects of pressure distribution of atypical buildings were investigated experimentally and numerically for various wind direction. The values of the mean external pressure coefficient were evaluated and the impact of turbulence models was observed and evaluated using statistical methods.

The following results were obtained:

- The choice of a turbulent model has a significant influence on the results achieved.

- From the statistical analysis and comparison of the results, SST model $k-\omega$ was evaluated as the most suitable.

- The open question is what accuracy is required in order to be able to claim that the chosen turbulent model is suitable for application in wind engineering.

- The influence of the surrounding objects is significant, it most affected the zones and sizes of the suctions, the pressed area is slightly reduced, due to the shielding effect of the cylinder-shaped building.

- From the point of view of reducing the external wind pressure factor mean $c_{p e}$, an arrangement with a wind direction of $0^{\circ}$ is more appropriate when both buildings are in alignment.

- The suction areas increased when the nearby cylinder-shaped building produced an amplification effect, which was observed at angles of 90 and $135^{\circ}$, see Fig. 5. 


\section{Acknowledgements}

This work was supported by the Slovak Research and Development Agency under contract no. APVV-16-0126, APVV-19-0460 and by the Scientific Grant Agency of the Ministry of Education, Science, Research and Sport of the Slovak Republic and the Slovak Academy of Sciences in the project VEGA 1/0113/19.

\section{References}

[1] STATHOPOULOS, T.: Computational wind engineering: past achievements and future challenges. Journal of Wind Engineering and Industrial Aerodynamics, Vol. 67-68, 1997, pp. 509-532, https://doi.org/10.1016/S0167-6105(97)00097-4.

[2] BAKER, C. J.: Wind engineering - past, present and future. Journal of Wind Engineering and Industrial Aerodynamics, Vol. 95, 2007, pp. 843-870, https://doi.org/10.1016/j.jweia.2007.01.011.

[3] BLOCKEN, B.: 50 years of computational wind engineering: past, present and future. Journal of Wind Engineering and Industrial Aerodynamics, Vol. 129, 2014, pp. 69-102, https://doi.org/ 10.1016/j.jweia.2014.03.008.

[4] BLOCKEN, B.: Computational Fluid Dynamics for urban physics: Importance, scales, possibilities, limitations and ten tips and tricks towards accurate and reliable simulations. Building and Environment, Vol. 91, 2015, pp. 219-245, https://doi.org/10.1016/j.buildenv.2015.02.015.

[5] MOK, W. K. - CHOW, W. K.: Verification and validation in modeling fire by computational fluid dynamics. International Journal on Architectural Science, Vol. 5, Iss. 3, 2004, pp. 58-67, https://www.bse.polyu.edu.hk/researchCentre/Fire_Engineering/summary_of_output/journal/IJAS/V 5/p.58-67.pdf.

[6] CHARNEY, J. G.: The use of the primitive equations of motion in numerical prediction. Tellus, Vol. 7, 1955, pp. 22-26, https://doi.org/10.1111/j.2153-3490.1955.tb01138.x.

[7] SMAGORINSKY, J.: On the numerical integration of the primitive equations of motion for baroclinic flow in a closed region. Monthly Weather Review, Vol. 86, Iss. 12, 1958, pp. 457-466, https://doi.org/10.1175/1520-0493(1958)086<0457:OTNIOT>2.0.CO;2.

[8] MURAKAMI, S. - MOCHIDA, A.: Past, present and future of CWE. The view from 1999. Proceedings of the 10th International Conference on Wind Engineering, Copenhagen, 1999, pp. 91-104.

[9] MURAKAMI, S.: Overview of turbulence models applied in CWE-1997. Journal of Wind Engineering and Industrial Aerodynamics, Vol. 74-76, 1998, pp. 1-24, https://doi.org/10.1016/ S0167-6105(98)00004-X.

[10] RICHARDS, P. J. - HOXEY, R. P.: Appropriate boundary conditions for computational wind engineering models using the $k-\varepsilon$ turbulence model. Computational Wind Engineering 1, Elsevier, 1993, pp. 145-153, https://doi.org/10.1016/B978-0-444-81688-7.50018-8.

[11] BLOCKEN, B. - STATHOPOULOS, T - CARMELIET, J.: CFD simulation of the atmospheric boundary layer: wall function problems. Atmospheric Environment, Vol. 41, Iss. 2, 2007, pp. 238 252, https://doi.org/10.1016/j.atmosenv.2006.08.019.

[12] FRANKE, J. - HELLSTEN, A. - SCHLÜNZEN, H. - CARISSIMO, B.: Best practice guideline for the CFD simulation of flows in the urban environment. COST Office, 2007.

[13] YANG, Y. - GU, M. - CHEN, S. - JIN, X.: New inflow boundary conditions for modelling the neutral equilibrium atmospheric boundary layer in computational wind engineering. Journal of Wind Engineering and Industrial Aerodynamics, Vol. 97, Iss. 2, 2009, pp. 88-95, https://doi.org/ 10.1016/j.jweia.2008.12.001.

[14] MURAKAMI, S. - MOCHIDA, A.: Three-dimensional numerical simulation of turbulent flow around buildings using the $k-\varepsilon$ turbulence model. Building and Environment, Vol. 24, Iss. 1, 1989, pp. 51-64, https://doi.org/10.1016/0360-1323(89)90016-4.

[15] MURAKAMI, S. - MOCHIDA, A. - HAYASHI, Y. - SAKAMOTO, S.: Numerical study on velocitypressure field and wind forces for bluff bodies by $k-\epsilon$, ASM and LES. Journal of Wind Engineering and Industrial Aerodynamics, Vol. 44, Iss. 1-3, 1992, pp. 2841-2852, https://doi.org/10.1016/ 0167-6105(92)90079-P.

[16] MURAKAMI, S.: Comparison of various turbulence models applied to a bluff body. Journal of Wind Engineering and Industrial Aerodynamics, Vol. 46-47, 1993, pp. 21-36, https://doi.org/ 10.1016/0167-6105(93)90112-2.

[17] JONES, W. P. - LAUNDER, B. E.: The prediction of laminarization with a two-equation model of turbulence. International Journal of Heat and Mass Transfer, Vol. 15, Iss. 2, 1972, pp. 301-314, https://doi.org/10.1016/0017-9310(72)90076-2. 
[18] SHIH, T. - LIOU, W. W. - SHABBIR, A. - YANG, Z. - ZHU, J.: A new k- $\epsilon$ eddy viscosity model for high reynolds number turbulent flows. Computers \& Fluids, Vol. 24, Iss. 3, 1995, pp. 227-238, https://doi.org/10.1016/0045-7930(94)00032-T.

[19] WILCOX, D. C.: Turbulence modeling for CFD. Vol. 2, 1998, pp. 103-217 La Canada, CA: DCW industries.

[20] MENTER, F. R.: Two-equation eddy-viscosity turbulence models for engineering applications. AIAA Journal, Vol. 32, Iss. 8, 1994, pp. 1598-1605, https://doi.org/10.2514/3.12149.

[21] HUBOVÁ, O - LOBOTKA, P.: The Multipurpose New Wind Tunnel STU. Civil and Environmental Engineering, Vol. 10, Iss. 1, 2014, pp. 1-9, https://doi.org/10.2478/cee-2014-0001.

[22] STN EN 1991-1-4, Eurocode 1: Actions on structures. Part 1-4: General actions. Wind actions, Slovak Office of Standards, Metrology and Testing, 2007.

[23] CERMAK, J. E. et al.: Wind Tunnel Studies of Buildings and Structures: ASCE Manuals and Reports on Engineering Practice, 1999, Virginia: American Society of Civil Engineers.

[24] MEDVECKÁ, S - IVÁNKOVÁ, O. - MACÁK, M. - MICHALCOVÁ, V.: Determination of Pressure Coefficient for a High-rise Building with Atypical Ground Plan. Civil and Environmental Engineering, Vol. 14, Iss. 2, 2018, pp. 138-145, https://doi.org/10.2478/cee-2018-0018.

[25] TOMINAGA, Y. - MOCHIDA, A. - YOSHIE, R. - KATAOKA, H. - NOZU, T. - YOSHIKAWA, M. SHIRASAWA, T.: AlJ guidelines for practical applications of CFD to pedestrian wind environment around buildings. Journal of Wind Engineering and Industrial Aerodynamics, Vol. 96, Iss. 10 - 11, 2008, pp. 1749-1761, https://doi.org/10.1016/j.jweia.2008.02.058.

[26] VAN HOOFF, T. - BLOCKEN, B.: Coupled urban wind flow and indoor natural ventilation modelling on a high-resolution grid: a case study for the Amsterdam ArenA stadium. Environmental Modelling and Software, Vol. 25, Iss. 1, 2010, pp. 51-65, https://doi.org/10.1016 /j.envsoft.2009.07.008.

[27] ANSYS Fluent Theory Guide, ANSYS, Inc., 275 Technology Drive Canonsburg, PA 15317, November 2020.

[28] CHANG, J. C. - HANNA, S. R.: Air quality model performance evaluation. Meteorology and Atmospheric Physics, Vol. 87, 2004, pp. 167-196, https://doi.org/10.1007/s00703-003-0070-7 